II.

\title{
Vollständige Heilung eines Falles von primärem Carcinom des Gehörorgans.
}

Yor

August Lueae in Berlin.

Unter diesem Titel publizierte ich im Jahre 1887 in der November-Nummer der Therapeutischen Monatshefte aus meiner früheren Klinik den Fall eines bei der Aufnahme 31jährigen Maurers, welcher vom November 1880 bis Februar 1884 in poliklinischer Behandlung stand. Es bandelte sich um ein rom äußeren Gehörgang und vom Trommelfelle mit eitriger perforativer Mittelohrentzündung ausgehendes Cancroid, welches nach jedem operativen Eingriff zunahm, während die Anwendung eines zu gleichen Teilen ans Pulv. Herb. Sabinae und Alum. ust. bestehenden Streupulvers das Wachstum der Geschwulst unter Nachlaß der mit dieser verbundenen Schmerzen zum Stillstand brachte und schließlich zur vollständigen Heilung mit Wiederherstellung des stark herabgesetzten Gehörs führte.

Aus der dermaligen Krankengeschichte sei hier zur Orientierung nur Folgendes kurz bemerkt.

Pat., dessen Tante väterlicherseits an "Unterleibskrebs" verstorben war, hatte 6 Monate früher zuerst einen rechtsseitigen blutigen Ausfluß aus dem Ohr und später eine sich unter großen Schmerzen im Ohre bildende Geschwulst bemerkt, deren Wachstum weder durch Ätzungen noch durch Wegnahme mit dem scharfen Löffel verhindert werden konnte.

Bei der Aufnahme des Pat. war der äußere Gehörgang von einer blaßrötlichen „polypösen“, gegen Berührung sehr sehmerzhaften Geschwulst vollständig gefüllt. Fötide, stinkende Eiterung und mäßige Schwellung der Drüsen unter der Ohrmuschel, die ganze Gegend hinter, unter und vor dem Ohre auf Druck sehr 
schmerzhaft, aber ohne jede Schwellung des Warzenfortsatzes. Fl. (für 3 und Friedrich) nur am Ohr gehört. Ein bohnengroßes mit dem scharfen Löffel entferntes Stück der Gesehwulst, wurde dem weiland pathologischen Anatomen Carl Friedländer zur Untersuchung übergeben, welcher erklärte, daß hier ein selten typischer Fall von Cancroid mit reichlichen, konzentrisch geschichteten Hornperlen vorliege. Charakteristich war, daß die Geschwulst nach kurzem Nachlaß der Schmerzen wieder zunahm. Dasselbe war der Fall, als Ende 1880 noch einmal mit gleichem bistologischen Resultat ein Stiick entfernt worden war.

Infolgedessen enthielt ich mich jedes weiteren operativen Eingriffs, beschränkte mich auch sehr bald auf den Foetor beseitigende Einspritzungen mit verdünntem Chlorwasser und verordnete das obige Pulver, welches Anfangs von uns in der Poliklinik, später vom Pat. selbst zu Hause eingeblasen wurde.

Da Pat. sehr bald hierbei wieder arbeitsfähig wurde, tat er dies sehr unregelmäBig, und nahm beim jedesmaligen Aussetzen des Mittels die Geschwulst wieder zu, bis endlich bei energischer Durchführung dieser Behandlung Anfang 1884 vollständige Heilung unter Vernarbung der Trommelfellperforation erfolgte, so dab ich nach weiterer dreijähriger Beobachtung wohl berechtigt war, diesen Fall im Jahre 1887 als vollständig geheilt zu publizieren.

In meiner damaligen Epikrise erklärte ich dieses Unikum von Heilung eines Ohrkarcinoms dadurch, daß die allen ähnlichen Fälen gemeinsame initiale Eiterung erst seit 6 Monaten bestand, der Tumor ohne nachweisbare Beteiligung des Mittelohres auf den äußeren Gehörgang: und das Trommelfell beschränkt blieb, vor allem aber den Knochen noch nicht ergriffen hatte und keine Fazialparalyse vorhanden war, während das letztere Symptom in keinem der bisher beobachteten, letal endenden Fälle fehlte. -

Soweit meine damaligen Beobachtungen. Der Zufall wollte, daß im April 1894 der sich sonst durchaus wohl befindende und gut hörende Pat. wieder in der Poliklinik untersucht werden konnte. Wir entdeckten hierbei ein beginnendes Recidiv der Geschwulst in Gestalt einer kleinen von der vorderen Gehörgangswand ausgehenden, bei der Sondieruug leicht blutenden Exkrescenz. Das Trommelfell zeigte mit Ausnahme einer narbigen Trübung nichts Abnormes. Auf Grund der Erfahrung, daß jeder operative Eingriff das Wachstum des Tumors beschleunigt hatte, verordnete ich wieder die Einblasungen des frïher bewährten Mittels, 
welches in etwa 14 Tagen vollständige Heilung erzielte. Pat. war dann zur Kontrolle noch dreimal in der Poliklinik und hörte ich seitdem nichts von ihm, bis er mir Ende Dezember 1906 einen dankerfüllten Brief über sein gutes Befinden schrieb und sich mir von neuem zur Untersuchung vorstellte. Das auf dem früher kranken Ohr mäßig herabgesetzte Gehör wurde durch Ausspritzen eines Ceruminalpfropfes vollständig hergestellt und zeigte der äuBere Gehörgang nichts Abnormes, das Trommelfell eine allgemeine Trübung; denselben Befund konnte ich am 28. Juni 1907 konstatieren. 